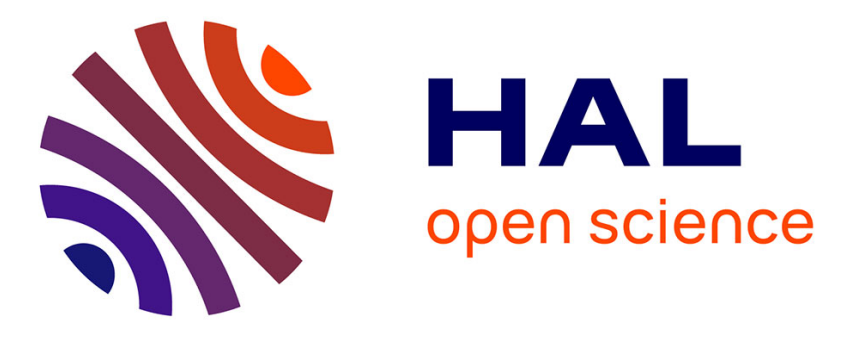

\title{
Measuring sound scattering coefficients of uneven surfaces in a reverberant workplace. Principle and validation of the method.
}

Joël Ducourneau, Adil Faiz, Adel Khanfir, Jacques Chatillon

\section{- To cite this version:}

Joël Ducourneau, Adil Faiz, Adel Khanfir, Jacques Chatillon. Measuring sound scattering coefficients of uneven surfaces in a reverberant workplace. Principle and validation of the method.. Applied Acoustics, 2013, 74 (5), pp.653-660. 10.1016/j.apacoust.2012.11.012 . hal-00968687

\section{HAL Id: hal-00968687 \\ https://hal.science/hal-00968687}

Submitted on 1 Apr 2014

HAL is a multi-disciplinary open access archive for the deposit and dissemination of scientific research documents, whether they are published or not. The documents may come from teaching and research institutions in France or abroad, or from public or private research centers.
L'archive ouverte pluridisciplinaire HAL, est destinée au dépôt et à la diffusion de documents scientifiques de niveau recherche, publiés ou non, émanant des établissements d'enseignement et de recherche français ou étrangers, des laboratoires publics ou privés. 


\author{
J. DUCOURNEAU ${ }^{1}$, A. FAIZ ${ }^{1}$. A. KHANFIR ${ }^{2}$, J. CHATILLON ${ }^{2}$ \\ ${ }^{1}$ Université de Lorraine, LEMTA, UMR 7563, \\ 2, avenue de la forêt de Haye, Nancy, F-54000, France \\ $\underline{\text { Joel.Ducourneau@pharma.uhp-nancy.fr }}$ \\ Adil.Faiz@pharma.uhp-nancy.fr \\ ${ }^{2}$ Institut national de recherche et sécurité (INRS) \\ Rue du Morvan CS 60027 \\ Vandœuvre-lès-Nancy, F-54519, France \\ Adel.Khanfir@inrs.fr \\ Jacques.Chatillon@inrs.fr
}




\begin{abstract}
In workplaces, wall facings are often based on periodic or aperiodic sound scattering surfaces. It is necessary to develop acoustic characterization methods for these kinds of walls to predict the acoustic pressure cartography in the room in order to improve the acoustical treatment. However, this characterization is quite difficult because of the partially reverberant conditions. We developed a measurement system which determines in situ the sound scattering coefficients of relief surfaces. The measurement method, originally operating in free-field conditions, was adapted for indoor use. To overcome problems of parasite echoes coming from reverberation and from noisy sources present on the site, we developed a dedicated emission/reception system. An acoustic antenna with constant directivity over the full frequency range allows spatial filtering of the parasite echoes and an impulsive sound source enables the use of a broad temporal window, resulting in adequate time separation of the different signals received by the antenna. Measurements of the sound scattering coefficient of a corrugated panel were carried out for several incidence angles in free-field and in a noisy workshop and allowed the in situ validation of this system.
\end{abstract}




\section{Introduction}

Sound diffusion mechanisms are involved in explaining the behaviour of scattering facings often present in industrial workplaces. To provide tools for better predicting the noise level at the workplace in order to propose the most appropriate acoustic treatments, measurement methods to determine the sound scattering coefficient of wall facings in industrial rooms are necessary. Many methods have been developed both to study the sound diffusion mechanisms and to quantify the various types of sound scattering coefficient.

The standard definition of the sound scattering coefficient is the ratio of the energy reflected outside the specular zone to the total reflected energy. Many other definitions of this coefficient exist in the scientific literature. Cox used a concept given by Schroeder [1] and proposed to quantify the diffusion uniformity by means of the standard deviation of the reflected energy distribution [2]. A similar approach for quantizing the diffusion of periodic surfaces was proposed by Takahashi [3]. Hargreaves [4] proposed a new diffusion uniformity coefficient based on the circular autocorrelation function of the polar reflected energy diagram. The circular autocorrelation function quantifies the similarity between different sections of the polar reflected energy diagram. Angus [5] also defined the spherical harmonics diffusion uniformity coefficient. He uses the fact that every hemispherical distribution of a scattering surface can be decomposed in a set of surface spherical harmonics, by analogy with Fourier analysis.

Further to these definitions, the main methods used to measure the sound scattering coefficient of uneven surfaces depend on the type of incident sound field: a free field or a diffuse field [6-7].

The Adrienne method [8] adapted for outdoor surfaces can separate the direct and reflected pulse by time windowing. The correction for spherical spreading of the sound wave by time multiplication of the impulse responses illustrates the originality of the Adrienne method.

The International Organization for Standardization (ISO) published a standard for measuring random incidence scattering coefficients of diffusers in a reverberation room [9]. The method can be applied on both real-scale sample rooms and on scale-down model rooms. The proposed measuring technique originates from the Vorländer and Mommertz method $[10]$. 
The method for measuring the autocorrelation diffusion uniformity coefficient has been standardized by the Audio Engineering Society (AES) [11].

Mommertz [12] proposed to determine the directional scattering coefficient based on polar reflection data, measured or calculated on a semicircle in the case of a single-plane diffuser. Farina developed a new measurement methodology for measuring both the diffusion uniformity coefficient and the scattering coefficient [13-14]. In this approach, numerous impulse responses are measured with a single microphone, repeatedly placed in subsequent positions in a straight line parallel to the diffuser.

In the Vorländer and Mommertz method [10], scattered energy is estimated on the energy loss by coherently averaging impulse responses. It is also possible to estimate this in a free field environment by coherently averaging reflected pulses only.

In this paper, we propose an adaptation of this free field method to determine the sound scattering coefficients of scattering surfaces present in reverberant workplaces. The experimental device used originally for measuring the sound absorption coefficients of flat surfaces in a workshop [15] has been adapted and improved to determine the sound scattering coefficients.

\section{Measurement of the sound scattering coefficient in free field}

The sound scattering coefficient is defined as the ratio of the reflected energy outside the specular zone to the total reflected energy:

$\delta=1-\frac{\int_{\Omega_{S}} E(\Omega) \mathrm{d} \Omega}{\int_{\Omega} E(\Omega) \mathrm{d} \Omega}$

with $\Omega_{\mathrm{S}}$ the solid angle corresponding to the specular zone and $\Omega$ the solid angle corresponding to all the reflected energy (see Fig.1).

A loudspeaker and a microphone are positioned in the specular direction under far field conditions. The scattering surface under investigation is fixed to a rotating plate such that 
measurements can be taken for several orientations (see Fig. 2). For an incidence $\theta_{\mathrm{s}}$ of the source and the receiver and for an orientation $\varphi_{\mathrm{i}}$, the reflected sound pressures $p_{r, \varphi_{i}}\left(t, \theta_{s}\right)$ can be expressed as the superposition of a diffuse $p_{\text {diff, } \varphi_{i}}\left(t, \theta_{s}\right)$ and a specular $p_{\text {spec }}\left(t, \theta_{s}\right)$ part [10]:

$p_{r, \varphi_{i}}\left(t, \theta_{s}\right)=p_{\text {spec }}\left(t, \theta_{s}\right)+p_{\text {diff }, \varphi_{i}}\left(t, \theta_{s}\right)$

The specular sound pressure is obtained for a significant number $\mathrm{n}$ of averaged acoustic reflected pressures following the angle $\varphi_{\mathrm{i}}(\mathrm{i}=1 \ldots \mathrm{n})$ : the specular part remains coherent with respect to $\varphi_{i}$, whereas the averaged diffuse part decreases:

$p_{\text {spec }}\left(t, \theta_{s}\right) \cong \frac{1}{n} \sum_{i=1}^{n} p_{r, \varphi_{i}}\left(t, \theta_{s}\right)$

In far field conditions, the total reflected energy averaged in the specular direction $\theta_{\mathrm{s}}$ can be expressed by the Fourier transform of the temporal acoustic pressures:

$E_{\text {tot }}\left(f, \theta_{s}\right)=K\left(f, \theta_{s}\right) \cdot \frac{1}{n} \sum_{i=1}^{n}\left|p_{r, \varphi_{i}}\left(f, \theta_{s}\right)\right|^{2}$

$K\left(f, \theta_{s}\right)$ depends on the acoustic power source, as well as the geometrical positions of the source and receiver. The specular reflected energy is also proportional to the square of the modulus of the Fourier transform of the specular acoustic pressure:

$E_{\text {spec }}\left(f, \theta_{s}\right)=K\left(f, \theta_{s}\right) \cdot\left|p_{\text {spec }}\left(f, \theta_{s}\right)\right|^{2}$

By combining equations (3), (4) and (5), we obtain the sound scattering coefficient in a specular direction:

$\delta\left(f, \theta_{S}\right)=\frac{\sum_{i=1}^{n}\left|p_{r, \varphi_{i}}\left(f, \theta_{S}\right)\right|^{2}-\frac{1}{n}\left|\sum_{i=1}^{n} p_{r, \varphi_{i}}\left(f, \theta_{S}\right)\right|^{2}}{\sum_{i=1}^{n}\left|p_{r, \varphi_{i}}\left(f, \theta_{S}\right)\right|^{2}}$ 
with $n>>1$

From these various sound scattering coefficients $\delta\left(f, \theta_{s}\right)$, it is possible to deduce the sound scattering coefficient for random incidence [16]:

$\delta(f)=\int_{0}^{\pi / 2} \delta\left(f, \theta_{s}\right) \sin \left(2 \theta_{s}\right) d \theta_{s}$

In this study, we decided to adapt the Vorländer and Mommertz measurement method described in this paragraph to noisy reverberant conditions in order to determine the sound scattering coefficient of scattering facings in industrial workplaces. To this end, we used an acoustic array with constant frequency directivity [17] as the receiver and an impulsive source [15]. Our work involved validating this method experimentally for a sample of a sinusoidal surface.

\section{Directive receiving system and impulsive source}

\subsection{Acoustic array using multipolar weighting}

A linear array using multipolar weighting has been designed to produce a directivity with a narrow main lobe which is constant in frequency and attenuated side lobes [17]. The directivity of an antenna with a first order multipolar weighting is proportional to $\cos (\theta)$. To obtain a narrower directivity, it is necessary to increase the order $\mathrm{N}$ of the spatial derivation to reach a directivity varying with $\cos ^{N}(\theta)$. If the antenna comprises 5 sensors, then 4 spatial derivatives must be calculated to obtain a directivity of the form $\cos ^{4}(\theta)$. To eliminate the rear lobe in this kind of directivity, the technique uses the cosine function properties: the $\mathrm{N}^{\text {th }}$ derivative (cosine to odd powers) and the $\mathrm{N}-1^{\text {th }}$ derivative (cosine to even powers) resulting from the successive spatial derivations are odd and even functions respectively. By summing these two functions, the values in the directivity diagram, corresponding to the angles in the $\pi$ to $-\pi / 2$ and $+\pi / 2$ to $+\pi$ ranges are practically suppressed [17]. 
The receiving linear antenna is composed of calibrated microphones with mutual phase mismatches that do not exceed $0.5^{\circ}$. This phase difference is very weak but still enough to cause, at low frequencies, instabilities at the main lobe level. To avoid this problem and to produce a constant level over a wide frequency range, several sub-arrays are used. The final receiving system contains 4 antennae, each using 5 sensors spaced in multiples of $2.5 \mathrm{~cm}$ apart. It contains, on the whole, 13 sensors. The spacing between the microphones for each sub-array is $2.5 \mathrm{~cm}, 5 \mathrm{~cm}, 10 \mathrm{~cm}$ and $15 \mathrm{~cm}$. The array is $60 \mathrm{~cm}$ long (Fig. 3).

Fig. 4 shows, respectively, the theoretical and the experimental directivity diagram produced by the receiving system using multi-polar weighting with a point source placed $1.5 \mathrm{~m}$ from the array centre. The experimental diagram is comparable to the theoretical one. The multipolar weighting provides a constant main lobe versus frequency. The secondary lobes are efficiently attenuated by more than $30 \mathrm{~dB}$. The directivity measured is in agreement with the characteristics expected over a wide spectral range extending from $150 \mathrm{~Hz}$ to $5000 \mathrm{~Hz}$.

\subsection{Impulsive source}

The impulsive source was generated from the inverse impulsive response of an emission system. This inverse filtering technique was used to calculate the signal source required to equalize the emission system response in order to generate short impulsions. The emission system integrated an equalizer (Yamaha Equalizer GQ 1031 BII), an amplifier (APK 2000) and a $10 \mathrm{~cm}$ diameter loudspeaker (Pioneer TS E1077). The emission system transfer function $\mathrm{H}(\mathrm{f})$ was measured in free field conditions with a MLS signal source, which was then filtered by the emission system impulsive inverse response and emitted at the input to generate a very short impulse. It is important to note that the emission system impulsive inverse response featured very high low frequency values because the loudspeaker could not emit sound energy in this frequency range. A high pass filter (frequency cut off set to $100 \mathrm{~Hz}$ ) was therefore necessary to prevent loudspeaker destruction resulting from the excessively high amplitude required by the inverse impulsive response.

Fig 5 shows the emission system impulsive response with and without the inverse impulsive response filtering technique [15]. 


\section{Measurement of the sound scattering coefficient of a sinusoidal surface}

\subsection{Description of the experimental device}

Measurements were taken in a noisy industrial workshop. Workplace reverberation time was measured at several positions using an alarm gun and a B\&K 2260 sound level meter. The average reverberation times per octave band are shown in Table 1. The background noise and the source level have been measured by the microphone at the array center with and without the multipolar weighting in order to show:

- how much the acoustic environment (see Figure 6 a) where the measurements have been carried out is noisy. In this acoustic condition, the Signal-to-Noise Ratio per octave presents some negative values per octave band (see Table 2),

- the acoustic array spatial filtering performance (see Figure $6 \mathrm{~b}$ ): the background noise has been attenuated more than $30 \mathrm{~dB}$ for some octave bands and the Signal-to-Noise Ratio became widely positive (see Table 2).

The system used for these measurements included a gate, an impulsive source and a directive array, as shown in Figures 7 and 8. For the impulsive source, the MLS signal source filtered by the emission system impulsive inverse response has been so emitted to obtain very short impulses in these noisy and reverberant conditions. The acoustic centres of the source and the antenna were both positioned in specular direction $\theta_{\mathrm{S}}$ as per the Vorländer and Mommertz method. In this specular direction, the directivity of the acoustic array doesn't modify the reflected echoes amplitudes because their propagation direction is so in the middle of the directivity main lobe. For a direction different from the specular one, it would be effectively necessary to take into account the directivity of the array.

This specular direction could of course be adjusted from $0^{\circ}$ to $90^{\circ}$ on the gate.

The gate could be rotated around the central axis of the scattering surface studied to give acquisitions based on angle $\varphi$. The distances between the source and the diffuse surface and between the receiver and the diffuse surface could be modified in the system. These distances were set to $1.20 \mathrm{~m}$ for all the measurements. 
The maximum dimension of the sinusoidal sample studied (see Fig. 9) was approximately 4.5 $\mathrm{m}$, so these distances were short and both the receiver and source were located in the acoustic near field. Under these conditions, we observed intermittent acoustic pressure amplitudes due to diffusion phenomenon [15]. However, it would have been very difficult for us to ensure far field conditions because the minimum far field distance (MFFD) for the frequency range studied was very large.

The angular variation of $\theta_{\mathrm{s}}$ and $\varphi$ discrete is made by applying $10^{\circ}$ increments.

Fig. 10 represents the impulsive signal responses received by the central sensor of the acoustic array without multipolar weighting (black curve). We clearly distinguish the source impulsive incident signal, the echo with its time oscillations caused by diffusion phenomenon and the interfering echoes due to reflections from the other wall facings. We notice that acoustic antenna directivity allows attenuation of these interfering echoes and conservation of only the diffuse echoes (grey curve).

As explained in Section 2, the specular sound pressure is obtained for a significant number of sound reflected pressures averaged for $\varphi$ variation. Fig. 11b shows the impulsive response obtained for a specular angle of incidence $\theta_{\mathrm{s}}=40^{\circ}$ resulting from superposition of 10 synchronized impulsive responses measured for several angles $\varphi$. Fig 11a also clearly shows that the specular part of this impulsive response is indeed clearly more visible than that obtained for only one angle $\varphi=30^{\circ}$.

Consequently, a time window $\mathrm{W}(\mathrm{t})$ with a sufficiently large width can be used. The applied window is constituted of a first half Blackman-Harris window of short duration $(1 \mathrm{~ms})$, followed by a $15 \mathrm{~ms}$ wide rectangular window and a final $5 \mathrm{~ms}$ half Blackman-Harris (Fig. 12a). This kind of window has been used for measuring the sound absorption coefficients of flat surfaces in a workshop [15]. This window is systematically placed such that its flat portion begins $0.2 \mathrm{~ms}$ before the specular reflected impulse. The first half Blackman-Harris window duration is only $1 \mathrm{~ms}$ because for high values $\theta_{\mathrm{s}}$, the incident impulsion and the specular part of the reflected pressure are very close. Due to this window width, the lower frequency limit is about $59 \mathrm{~Hz}$. The spectrum of such a window is shown in Fig. 12b; all the measurement results have gone through convolution with respect to this spectral window. 


\subsection{Results}

The graphs shown in Fig. 13 represent the variations in sound diffusion coefficient measured by $1 / 3$ octave bands for the sinusoidal surface described above. These measurements were compared with measurements taken in an anechoic room and with those obtained by Pauwels for the same type of surface profile [18]. Our measurements are similar to those of Pauwels. The specular part of the reflected energy effectively dominates at high angles of incidence with respect to the diffuse part of the reflected energy. In this case, the ratio of specular energy to total energy becomes 1 and measurement is therefore particularly error sensitive as the signals associated with sound incidence and reflection are very similar.

The measurement results for this industrial workshop are similar to those obtained both by Pauwels and in the anechoic room. This enables us to validate the method of sound diffusion coefficient measurement in a reverberating environment. It should be noted that the system was operating in unfavourable conditions in this case, i.e. in the presence of reverberation and a powerful disturbing source near the array. Inter-correlation to obtain the impulse response at each sensor allows us to separate the signal emitted by the source from the noise generated by the machine. This is because these signals are uncorrelated. Array spatial filtering attenuates the disruptive noise and the hall reverberation. Under these conditions, considered excessive, the system allows us to distinguish incident and reflected echoes clearly and thus to measure the sound diffusion of the wall facing under study. During a previous study conducted in 2009, sound absorption coefficients could be measured in conditions where the signal-tonoise ratio was $-10 \mathrm{~dB}[15]$.

\section{Conclusions}

Our research involves developing a system for measuring in situ the sound scattering coefficient of scattering wall facings in industrial workshops. Our technique is based on the free field method developed by Vorländer and Mommertz. We adapted this method to workplace reverberant conditions by introducing a directive acoustic array and an impulsive source used originally for measuring sound absorption. Experimental results allowed us to test and validate this new system in an industrial workshop [15]. A study of the relationship 
between the sound scattering coefficient measured and the apparent sound absorption of scattering facings is now required. To the end, measurements in a reverberant chamber are required to estimate this apparent sound absorption (Sabine absorption) for several scattering surface geometries.

\section{References}

[1] Schroeder M. R., Binaural dissimilarity and optimum ceilings for concert halls: More lateral sound diffusion, J. Acous. Soc. Am. Vol 65(4), 1979, p.958-963.

[2] Cox T.J., The optimization of profiled diffusers, J. Acous. Soc. Am. Vol 97 (5), 1995, p.2928-2936

[3] Takahashi D., Development of optimum acoustic diffusers, J. Acous. Soc. Jap. (E) Vol $16(2), 1995$, p.51-58.

[4] Hargreaves T. J., Cox J.T., Lam Y.W. D'Antonio P., Diffusion parameters for auditorium surfaces, Proceedings Institute of Acoustics, Vol 19 (3), 1997, p.19-27.

[5] Angus J. A. S., Diffuser assessment using surface spherical harmonics, $136^{\text {th }}$ meeting of ASA in J. Acous. Soc. Am., Vol 104 (3) part 2, 1998, p.1857-1858.

[6] Hargreaves T. J., Cox J.T., Lam Y.W., D’Antonio P., Surface diffusion coefficients for room acoustics: free-field measures, J. Acous. Soc. Am., Vol 108 (4), 2000, p. 17101720

[7] Characterization and measurement of surface scattering uniformity", AES-4id, Journal of the Audio Engineering Society, Vol 49 (3), 2001, p.148-165

[8] Anfosso F., Garai M., Clairbois J-P., Adrienne: une méthode européenne pour la qualification sur site des écrans antibruit, Bulletin de Liaison des Ponts et Chaussées, Vol 225, 2000

[9] Acoustics - Sound-scattering properties of surfaces - Part 1: Measurement of the random-incidence scattering coefficient in a reverberation room, ISO 17497, 2004

[10] Vorlander M., Mommertz E., Definition and measurement of random-incidence scattering coefficient, Applied Acoustics Vol 60, 2000, p187 - 199 
[11] AES, Characterization and measurement of surface scattering uniformity, AES-4id2001, Journal of the Audio Engineering Society, Vol 49 (3), 2001, p.148-165,

[12] Mommertz E., Determination of scattering coefficients from the reflection directivity of architectural surfaces, Applied Acoustics, Vol 60 (2), 2000, p.201-203

[13] Farina A., A new method for measuring the scattering coefficient and the diffusion coefficient of panels, Acustica - Acta acustica, Vol 86 (6), 2000, p.928-942.

[14] Farina A., Measurement of the surface scattering coefficient: comparison of the Mommertz/Vorländer approach with the new wave field synthesis method, International Symposium on Surface Diffusion in Room Acoustics, Liverpool, 2000

[15] Ducourneau J., Planeau V., Chatillon J., Nejade, A. Measurement of sound absorption coefficients of flat surfaces in a workshop. Applied Acoustics, Vol 70, 2009, p710-721

[16] De Geetere L., Analysis and improvement of the experimental techniques to assess the acoustical reflection properties of boundary surfaces, PhD, Catholic University of Leuven, Belgium, 2004

[17] Ducourneau J., Planeau V., Nejade, A. Design of a multipolar weighting for acoustic antennae. Applied Acoustics, Vol 70, 2009, p484-492

[18] Pauwells H., Diffusie tegenover geluidabsorptie: naar aangepaste experimenten. (Diffusion against sound absorption: towards suitable experiments), Master thesis, Catholic University of Leuven, Belgium, 2001 
Source

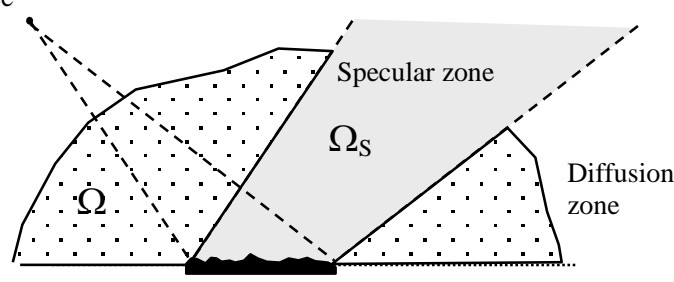

Scattering studied surface

Fig. 1: Specular and diffuse zone illustration 


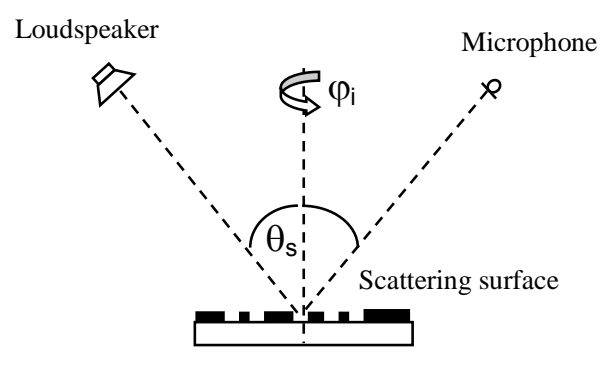

Fig. 2: Method to determine the sound diffusion coefficient in free field [10] 


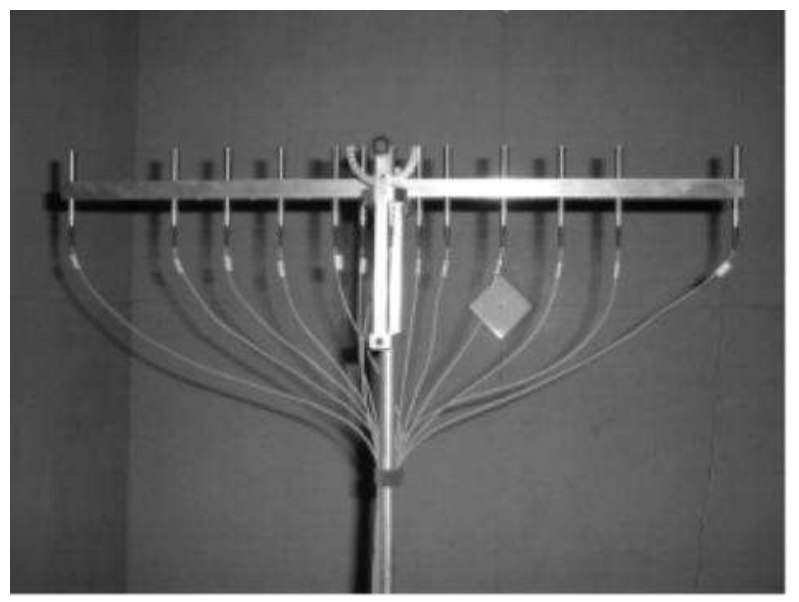

Fig. 3: Acoustic array comprising 13 microphones [17] 

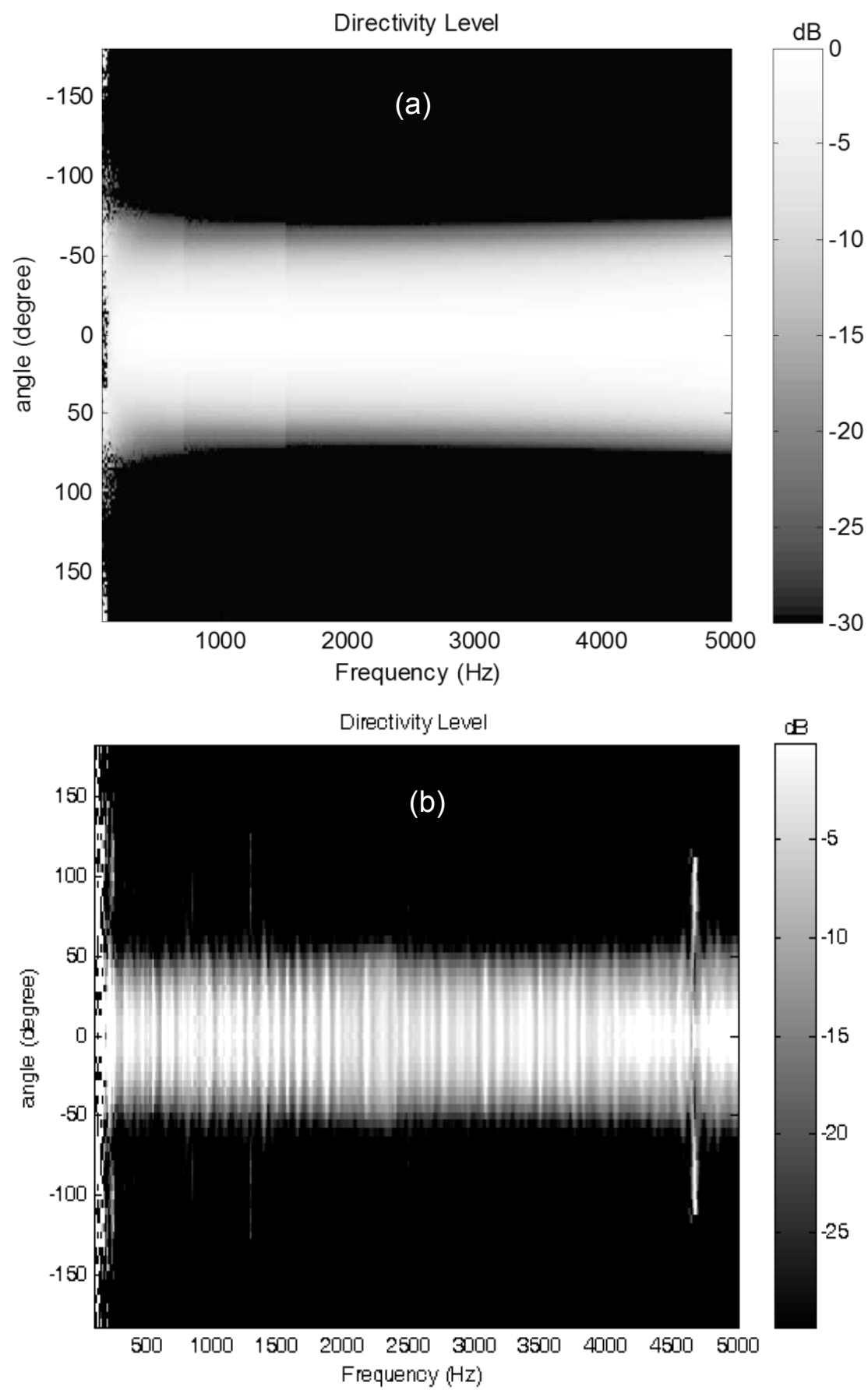

Fig. 4: Theoretical (a) and experimental (b) directivity diagram with respect to the angle $\theta$ and the frequency of the receiving system - Point source placed $1.5 \mathrm{~m}$ from the centre of the array [17] 

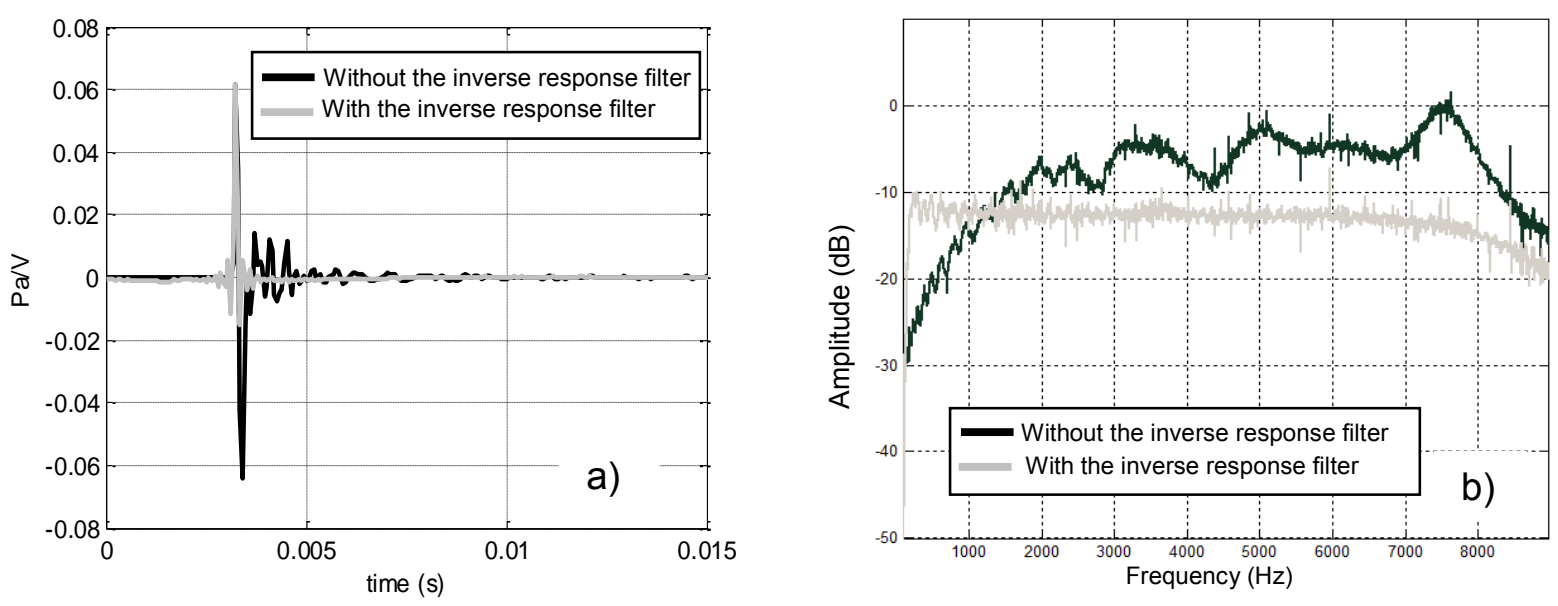

Fig. 5: Impulsive response of emission system a) in time - b) in frequency [15] 


\begin{tabular}{|c|c|c|c|c|c|c|c|}
\hline Octave $(\mathrm{Hz})$ & $\overline{125}$ & $\overline{250}$ & $\overline{500}$ & $\overline{1000}$ & $\overline{2000}$ & $\overline{4000}$ & $\overline{8000}$ \\
\hline $\operatorname{Tr}(\mathrm{s})$ & 1,6 & 1,7 & 2 & 2 & 1,8 & 1,4 & 0,9 \\
\hline
\end{tabular}

Table 1: Reverberation time of the hall workshop 

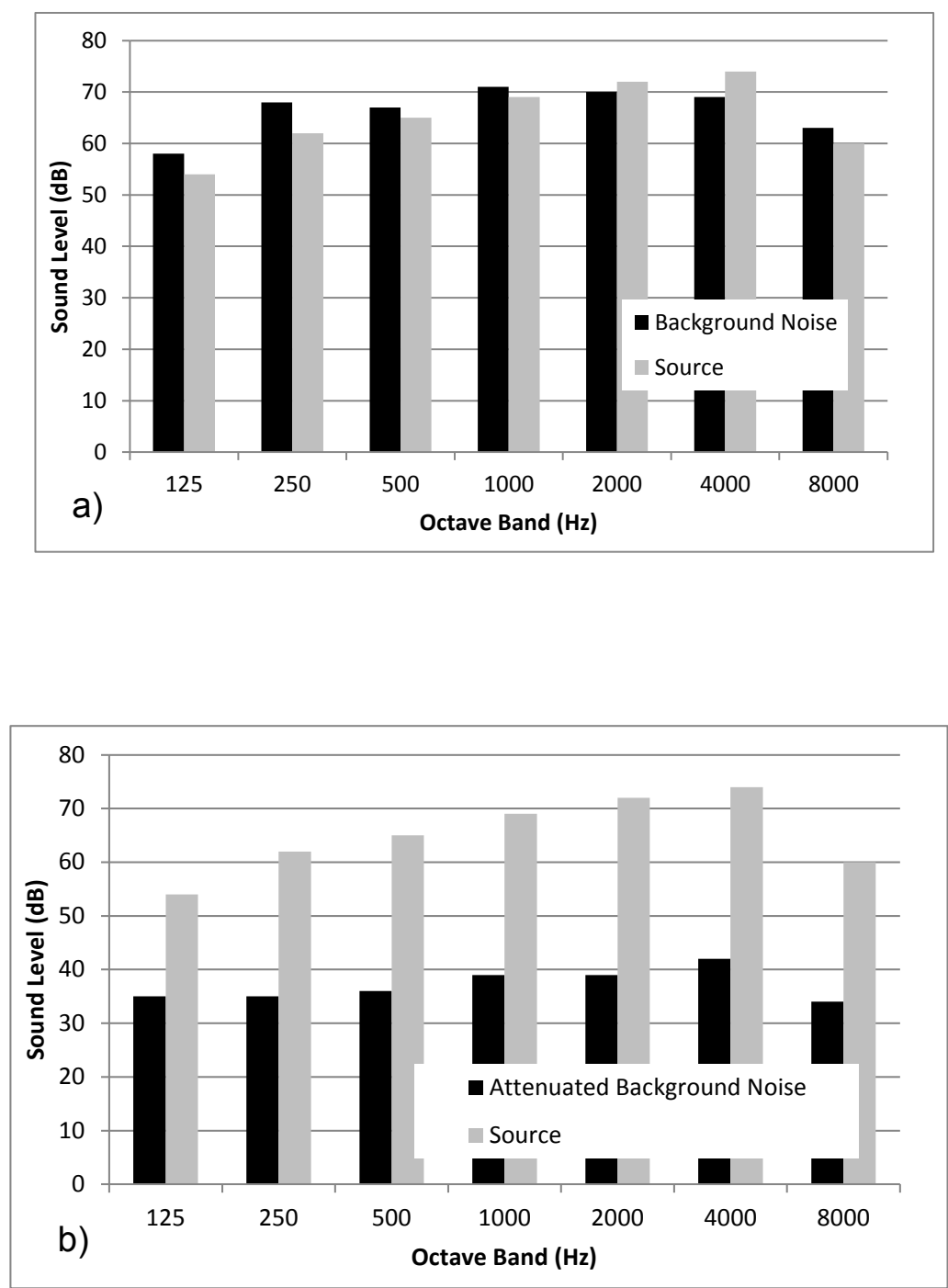

Fig. 6: The background noise and the source level per octave band a) without the acoustic array with multipolar weighting - b) with the acoustic array with multipolar weighting 


\begin{tabular}{|c|c|c|c|c|c|c|c|}
\hline Octave band (Hz) & 125 & 250 & 500 & 1000 & 2000 & 4000 & 8000 \\
\hline $\begin{array}{c}\text { SNR without the acoustic array with multipolar } \\
\text { weighting (dB) }\end{array}$ & -4 & -6 & -2 & -2 & 2 & 5 & -3 \\
\hline $\begin{array}{c}\text { SNR with the acoustic array with multipolar } \\
\text { weighting (dB) }\end{array}$ & 19 & 27 & 29 & 30 & 33 & 32 & 26 \\
\hline
\end{tabular}

Table 2: Signal-to-Noise Ratio per octave band with and without the acoustic array with multipolar weighting 


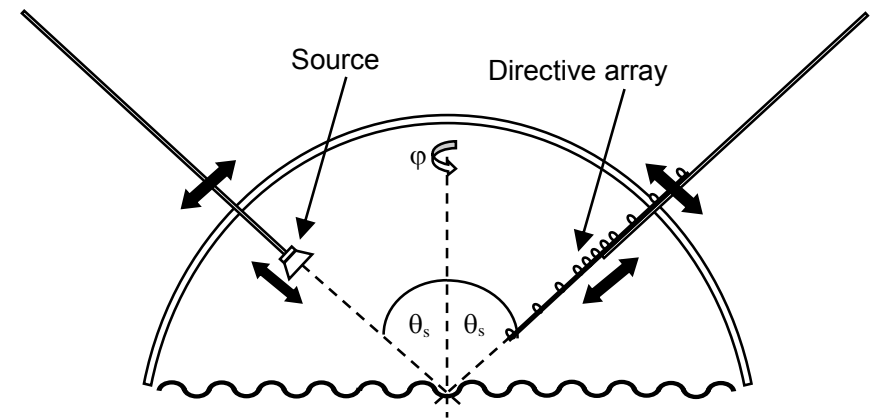

Fig. 7: Schematic diagram of the device 


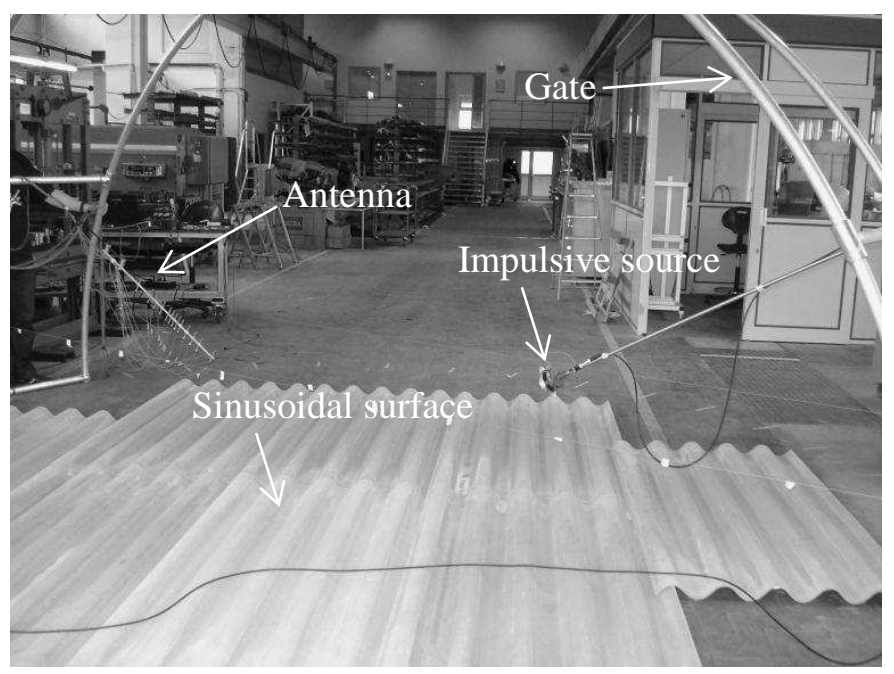

Fig. 8: Picture of the device 


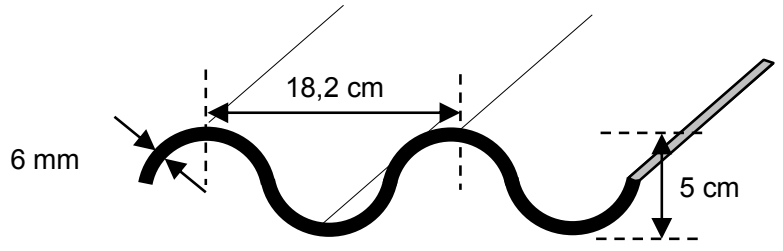

Fig. 9: Dimensions of the sinusoidal surface studied 


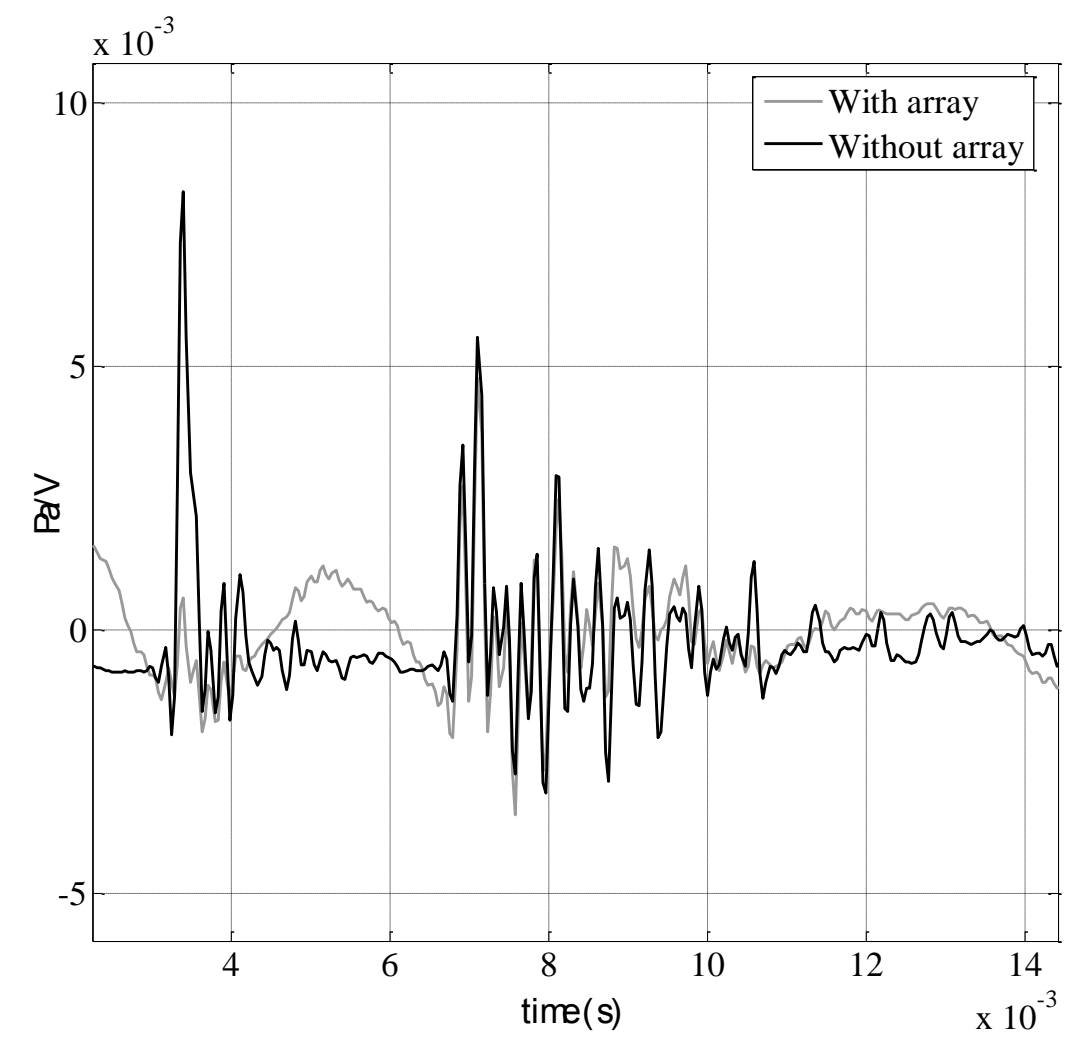

Fig. 10: Impulsive response received by the central sensor of the acoustic array (black curve) and by the acoustic array with multipolar weighting (grey curve) 

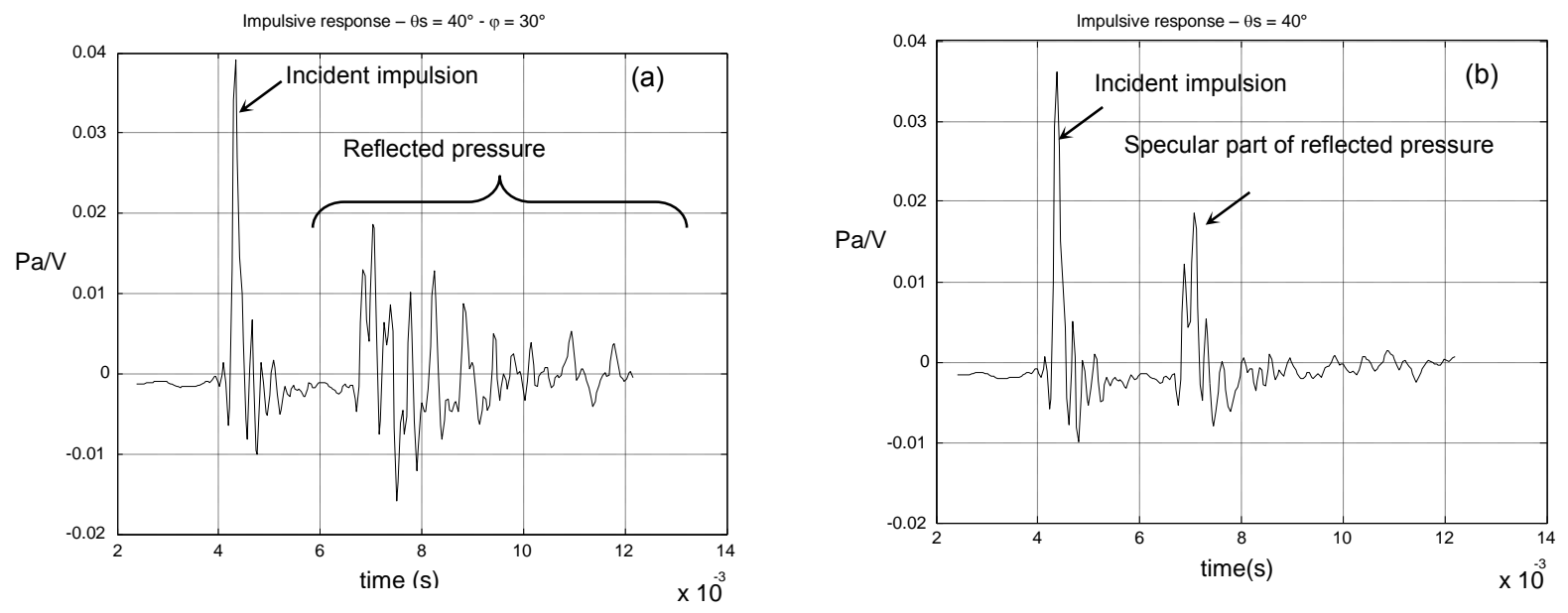

Fig. 11: Reflected impulsive responses obtained on the sinusoidal surface for $\theta_{\mathrm{s}}=40^{\circ}$ incident impulsion - a) $\varphi=30^{\circ}-$ b) averaged over $\varphi$ 

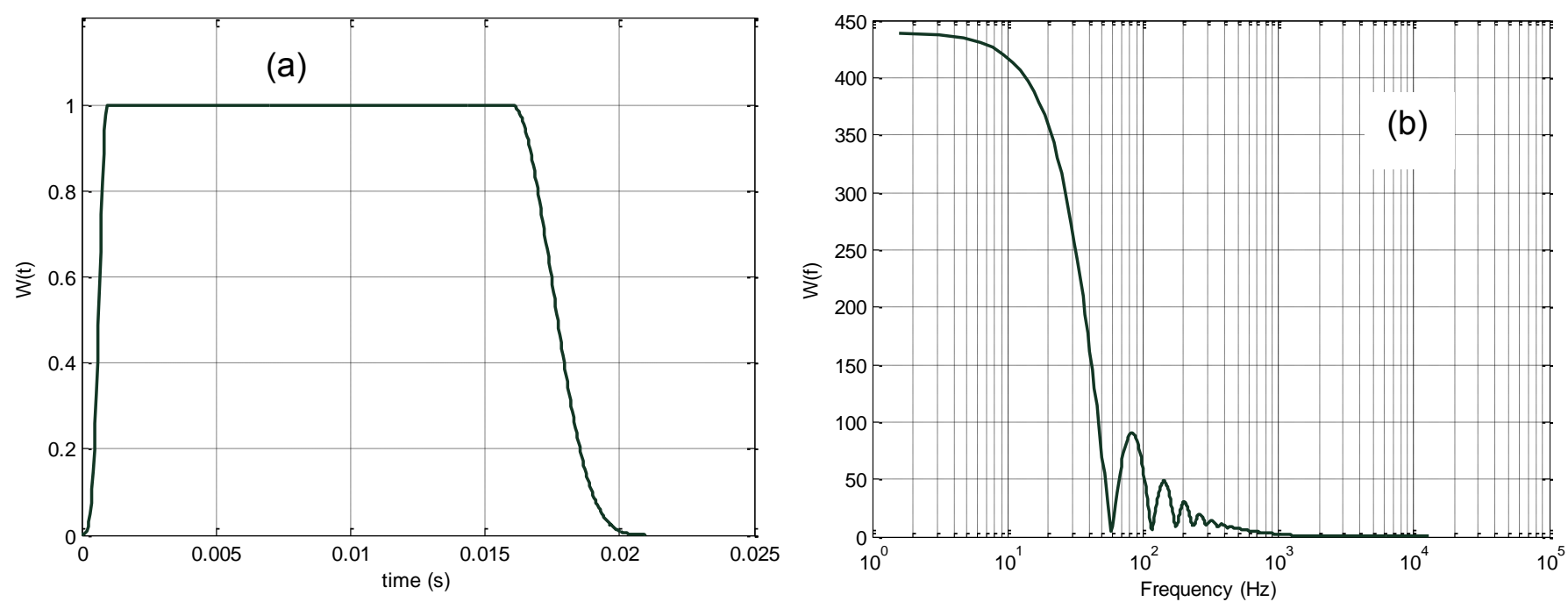

Fig 12: Window $\mathrm{W}(\mathrm{t})$ in the time domain (a), in the frequency domain (b) 
$\theta_{\mathrm{s}}=15^{\circ}$

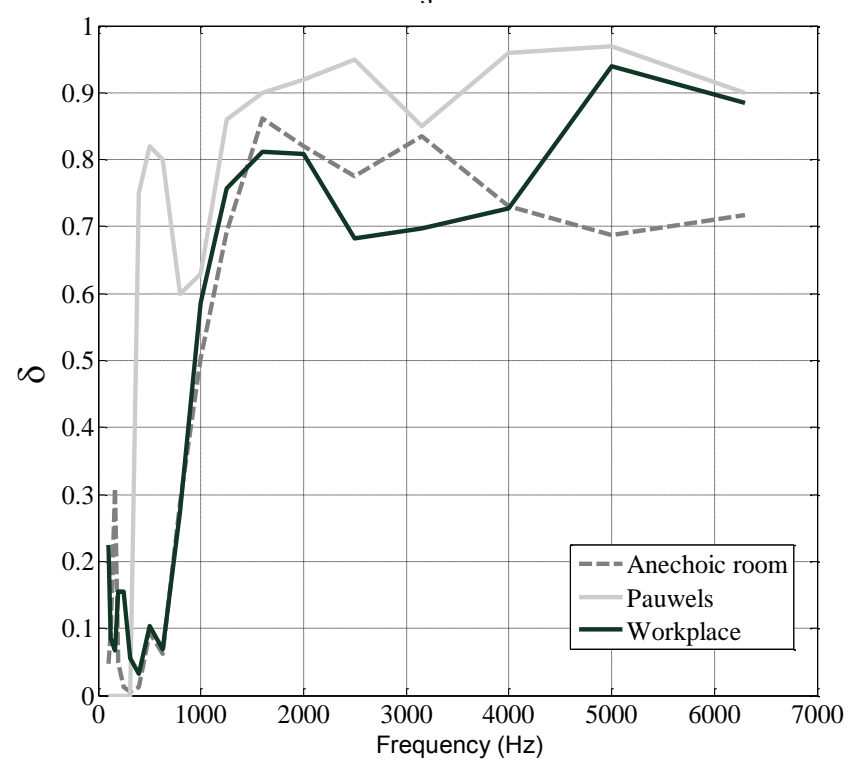

$\theta_{\mathrm{s}}=30^{\circ}$

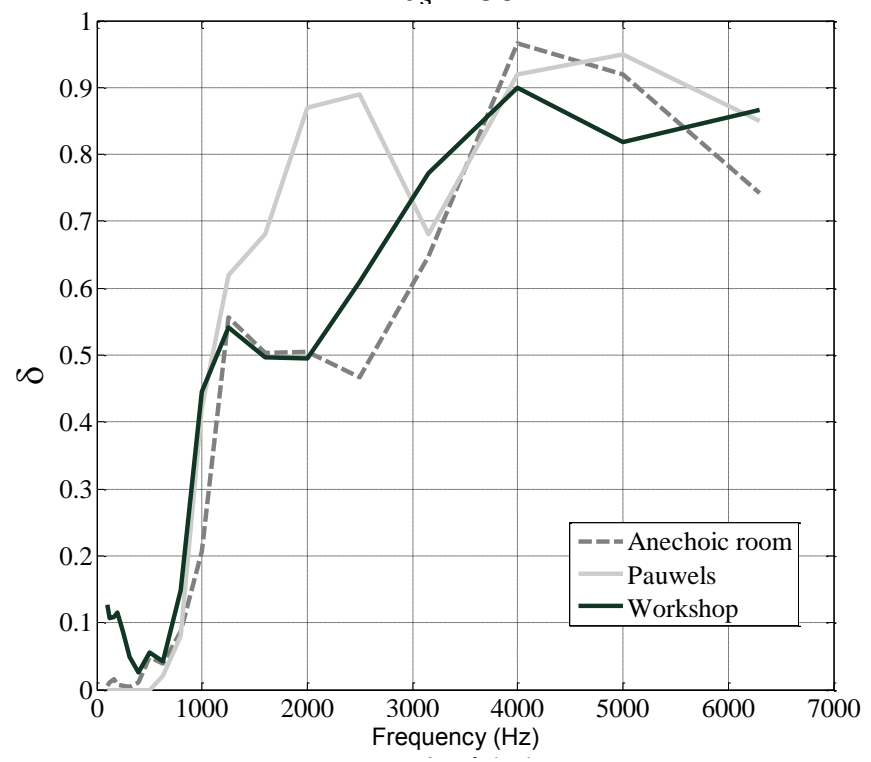

$\theta_{\mathrm{s}}=45^{\circ}$

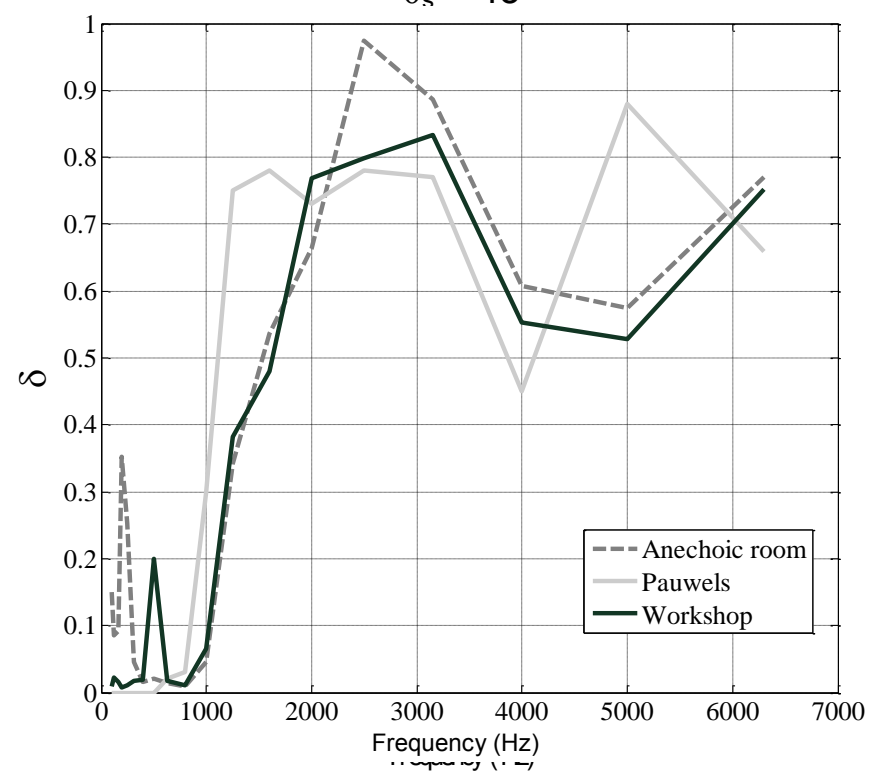

$\theta_{\mathrm{s}}=60^{\circ}$

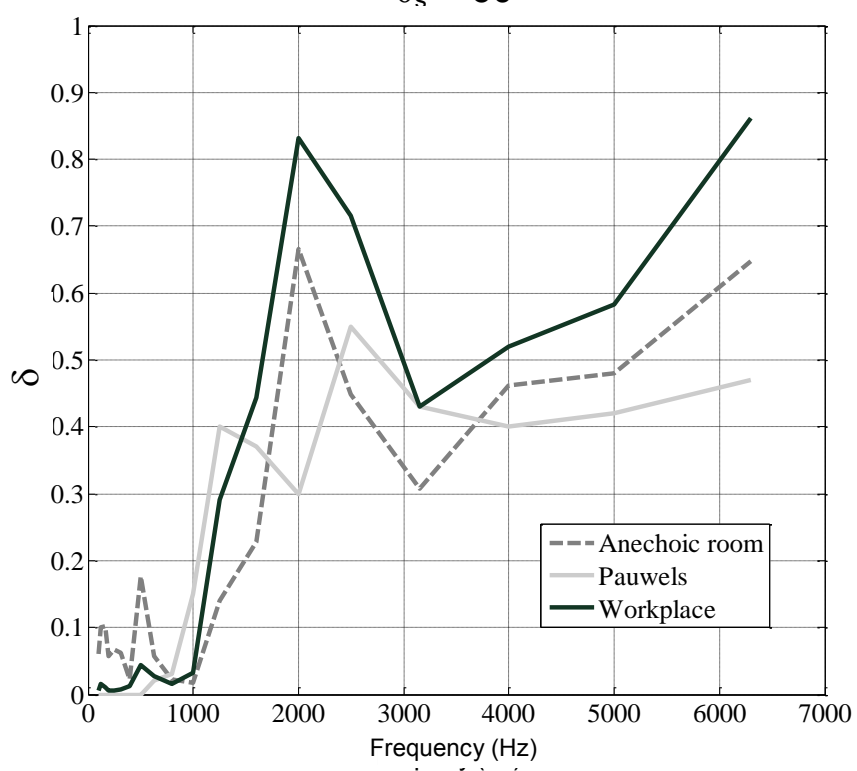

$\theta_{\mathrm{s}}=75^{\circ}$

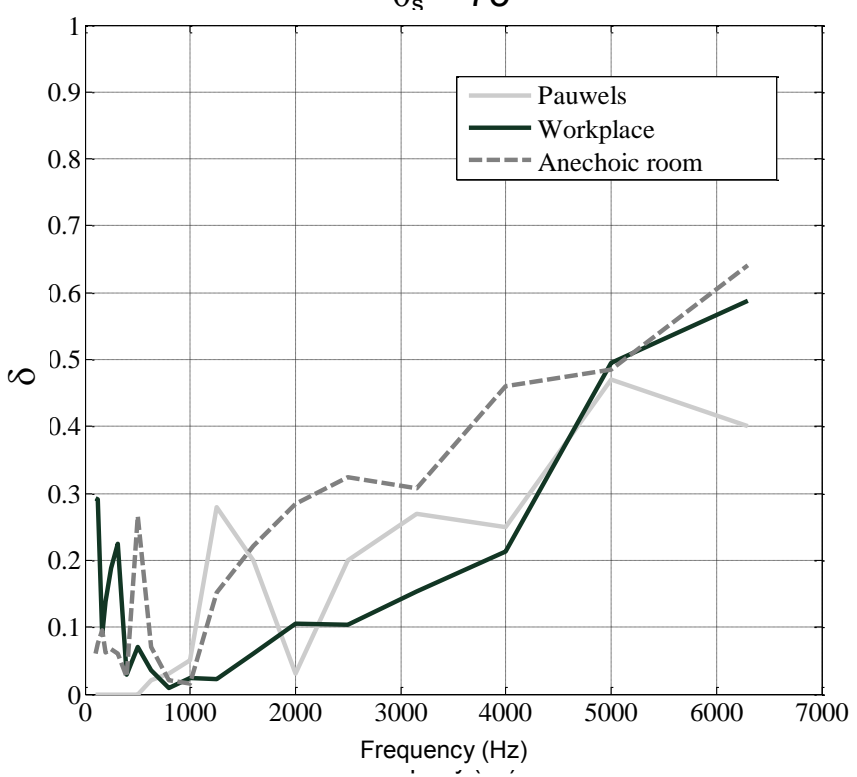

Fig. 13: Sound scattering coefficients obtained for angles of incidence $\theta_{\mathrm{s}}=15^{\circ}, 30^{\circ}, 45^{\circ}$, $60^{\circ}$ and $75^{\circ}$ respectively 